\title{
A model to evaluate logistics RFID-based investments economic effectiveness in the apparel field
}

\author{
Rinaldo Rinaldi* and Romeo Bandinelli \\ Industrial Department, University of Florence, Florence, Italy
}

\begin{abstract}
The paper presents a practical tool for supporting practitioners, consultants and researchers in the achievement of logistics effectiveness improvements in the fashion supply chain, through the determination of the expected profitability concerning RFID-based technology investments. Moreover, the limits related to the multipurpose implementation of this technology have been highlighted. The research explores the main cost items of an RFID based application, in order to understand to which extent the increased effectiveness, usually triggered by its implementation, is able to cover those costs. Main sources of knowledge are practitioners' report, scientific literature and case studies on the specific field. These investigations have conducted to the evidence that the RFID based applications and their investments are usually undertaken without a clear understanding of all the implications on the companies' P\&L (profit and loss): the tool presented has been designed to fill this gap, providing an easy-to-use algorithm to evaluate a priori the profitability of the investment.

The aim of this study is to support practitioners and managers in evaluating a priori the profitability of a RFID based investment in the fashion supply chain, understanding the related pay-back period (PBP); this indirectly will increase the success of RFID-based project implementations while reducing the uncertainty in terms of economical results.

The main contribute of this research resides in the model's ease of use, quickness and effectiveness, grossly defining the economical expectations of an RFID investment; given the difficulties in defining precise figures, the study could support the investment choices.
\end{abstract}

Keywords: RFID, return on investment, profitability, logistics, supply chain, fashion industry

\section{Introduction}

Radio Frequency Identification (RFID) and its related practical applications are widely growing in a variety of industries as an enabling technology adopted in order to increase the supply chain visibility (Taylor et al., 2003; Zahay \& Handfield, 2004) especially in those sectors characterized by a large movement of high value products (e.g. Pharma, Automotive, Luxury Goods).

Such a growth has been driven by several factors, generally linked by the necessity of a cost rationalization, for instance, the willingness to free employers from repetitive

\footnotetext{
${ }^{*}$ Corresponding author: Rinaldo Rinaldi, Industrial Department, University of Florence, Florence, Italy. E-mail: rinaldo.rinaldi@unifi.it.
} 
tasks (such as checking/ counting products in boxes) to switch them on more added value activities (Gaukelr \& Seifert, 2007).

In other cases, implementing an Auto-Identification system could prevent losses of revenues and of profitability, for example reducing counterfeiting, losses in warehouse or even reducing theft rates inside the factories (Veeramani et al., 2008).

In particular, the fashion industry is characterized by an increasing complexity, due to the globalization of sourcing and distribution. The main criticalities of fashion business include short product life cycle, high volatility, low predictability of demand and high purchasing impulse (Christopher et al., 2004; Bruce et al., 2004; Castelli et al., 2010, Bandinelli et al., 2013).

RFID technology has the potential to solve many key issues for the fashion supply chain (Bottani et al., 2009; Bertolini et al., 2012) and some studies have already suggested its possible application in this context. As an outcome of a recent survey (Osservatorio RFID, School of Management del Politecnico di Milano, "RFID: alla ricerca del valore", 2007), the most used applications considering the ones available in the field, are those related to some kinds of improvement in operations efficiency; more than $60 \%$ of the sample applications considered are running in Operations Support, Warehouse Logistics, Items Identification and Asset Management areas.

Moreover, the Aberdeen report (Aberdeen, 2005) about the main obstacle to the adoption of RFID-based solutions shows that the majority of the firms interviewed have encountered difficulties in the understanding of their validity, both in economical (measurable) terms and efficiency/effectiveness related (not measurable) ones. Other emerging barriers concern cost related issues, as infrastructure and tag costs (Bottani et al., 2009).

These evidences suggest the importance of the economic issue: RFID implementations cannot take off in a large scale because of the difficulties in pre-estimating the costs and benefits achievable. Logistics, as shown by the few implementations in the practical cases, might guarantee a minimum return on such investments but the amount of Return of Investment (ROI) and a precise Payback Period (PBP) have to be assessed. Most of the practitioners are not always able to conduct this evaluation, given the large number of the variables involved.

The present study provides a calculator tool to estimate a priori the impact of an RFID implementation in the fashion industry, taking into account Logistics purposes related to the estimation of Profit and Loss (P\&L), ROI and PBP.

\section{RFID economic evaluation: A brief state of the art}

A literature review conducted by the authors using the major science-specific search engines has shown to which extent the introduction of a RFID systems can provide significant benefits in different firms' areas, both at the strategic, operational and tactical levels (Bose \& Pal, 2005; Legnani et al., 2010). Even if most of the projects and application of the RFID Technology are related to the logistic area, where the benefits and the advantages are recognized both by researchers than practitioners, 
other significant areas where RFID can be applied emerge, generating a positive impact in the company business, e.g. the anti-counterfeiting and the traceability areas.

The results of the literature review have been classified according to three different topics. Section 2.1 deals with advantages and drawback of the RFId technology in the fashion industry. Section 2.2 reports the main barriers to the adoption of such technology, while Section 2.3 describes and compares several evaluation models developed in order to assess RFId investments.

\subsection{Advantages and drawback of the RFId technology in the fashion industry}

According to Tajima (2006) and Attaran (2010), the structural characteristics of radio frequency technology enable the achievement of benefits within each level of control in the company. In particular, RFID technology, enabling both the wireless multiple readings, which can be remotely monitored, and the unique identification of each item provided by the tag, allows companies to implement advanced solutions for track and tracing items along the supply chain (Bange, 2006).

This way, in the specific context of fashion, where the product life cycle is very short, the production is almost totally outsourced and there is a need of visibility and accuracy along the all supply chain, companies, through the analysis of their processes, are able to obtain benefits in terms of Accuracy, Productivity, Inventory management and Customer Relationship Management.

Concerning the Accuracy, the RFID technology reduces errors in the operations, shipping, receiving and picking processes and in the facilitation of exception handling. About the Productivity, the capabilities to automate the items identification and to increase availability and accuracy of information are the main benefits achievable, thanks to information systems and EPC system. This way, RFID is able to reduce lead times, to make more efficient the delivery process, to reduce the need for material handling, to improve asset management and space and to encourage information sharing. Concerning the Inventory level, through the increasing efficiency of processes and supply chain visibility, is able to reduce the need for stocks, limits the shrinkages (due to theft, abduction, expired products etc.) and counteracts the Bullwhip effect, i.e. the amplification of demand variability from downstream to upstream supply chain (Hardgrave et al., 2009). In the Customer Relationship Management, the RFID technology, particularly at the retail business level, enables significant improvements in terms of customer service and of shopping experience. Thanks to the enhanced accuracy of the information, a more efficient management of inventories occurs. Moreover a reduction in the need for safety stock is achievable, limiting the possibility of stock-out, thus guaranteeing a better customer service. The traceability linked to the production, can also generate benefits in the after-sales area, allowing the company to trace all the product's data, its origin, warranty, etc.

Furthermore, high expectations regarding this technology are related to the ability to create more sales opportunities and to improve the human understanding of the overall value related to the customers' shopping experience. The ability to obtain 
information on the customer's preferences, on the availability of sizes and colors, on the possibility to combine items, allowing product and service customization, and to achieve an increasing customer's loyalty represent very actual challenges.

Even if RFID can provide, as shown above, several benefits, obviously, the real advantages achievable depend on the implementation of RFID system. Roh et al. (2009) provide a classification of the possible applications, according to several dimensions (e.g. the number of organizations involved and the number of the technologies used).

Literature review has allowed us to find several case studies focusing on the benefits achievable through RFID. Loebbecke et al. (2006) analyze the implementation of RFID along the value chain of a manufacturer in the fashion industry, supported by the collaboration with the distribution center and its retailers. In this context, technology can significantly reduce cost and time management, also allowing visible improvements in the inventory management. Wessel (2006) show how, through the use of reusable tags, it is possible to increase the efficiency in apparel distribution and delivery processes. In particular, the company analyzed has achieved benefits in terms of ROI. This depends on the reuse of tag that reduces the cost of hardware, but also on the improvements in the inventory management, in the accuracy of processing orders, in the reduced shrinkage and in the increased delivery reliability. Choy et al. (2008) describe a management system of tissue samples based on RFID technology applied in a fashion industry, useful for the materials selection during the new product development phase. This reduces the time required for the selection process of tissue and increases efficiency in the new product development, enabling the ability to access more detailed information, accurate and constantly updated. Finally, Angeles (2005) highlighted the advantages attainable with the implementation of the systemsradio frequency identification, referring to seven case studies of leading companies in different market sectors. In this paper is reported how the potential of RFID has been used in order to improve the processes of product receiving, storage, supply, order fulfillment, shipping and transportation (traceability of products and assets). In the last part of the paper the author shows some main guidelines in order to develop an RFID system. In addition, to evaluate the ROI and the appropriate choice of the suitable RFID technology, the efforts to anticipate technical problems that may occur and to manage issues regarding IT infrastructure (data management and integration with other systems) are becoming more and more essential.

\subsection{Barriers to the adoption of RFID technology}

Several authors highlight the existence of barriers to the acquisition of this technology. In particular, here are reported the most common cited problems (Collins, 2004; Tajima, 2006; Moon \& Ngai, 2008; Keating et al., 2010, Lee \& Byoung-Chan, 2010).

Difficulties in RFID ROI calculation. Many suppliers who are involved in RFID adoption projects simply adapt the processes to the needs of their major customers. 
In these cases, generally, the suppliers choose to implement the so-called "slap-andship", which consists in the manually attachment of the tags just before the shipment, without obtaining any benefit from that operation. Moreover, high tags and hidden costs that can be generated by the change in the delivery processes, caused by the adoption of the RFID technology, trigger a possible negative ROI particularly in the short term period.

Technical risk. The technology is often seen as unreliable in order to guarantee a positive performance. In fact, the possibility of defective tags, false readings, issues regarding interferences caused by the presence of multiple readers, tags or other devices wirelessly connected (i.e. phone), difficulties in the integration with existing systems, the vulnerable to viruses, are seen as serious threats and can be considered high barriers in the adoption of this technology.

Popularity of the bar code technology. The presence of any business practice well established in the company, as the bar code technology, is a barrier for new technologies. In addition, costs and standardization achieved by the bar code technology are the main reasons why it is still a strong competitor of RFID (Gaukler \& Seifert, 2007).

Privacy. The potential invasion of privacy issues due to the use of RFID is considered to be, in certain industries, not a minor obstacle to its spread. Many companies' perplexities are related to the clients reaction and to the risk of a decreasing customer satisfaction. In the fashion industry, this is mainly due to different regulations and laws of the different markets worldwide.

Commitment. The involvement and acceptance of technology by the top management directly influence investment decisions. In general, projects that do not have a strong commitment by the management are often bound to failing. Equally important is a positive attitude to the training of employees, who have to learn how to use new systems and to use it daily.

These barriers are independent from the method used for the economic evaluation of the RFId investment and are common to all the investments carried out in the fashion industries. Moreover, the outcomes of the last research papers demonstrate that a structured approach to RFId project, with a reengineering of the processes involved in the technology adoption, can overcome these barriers and permit a successful application of the project.

\subsection{Evaluation models}

As RFID projects often compete with other IT projects given the lack in resources, the fundamental questions for RFID adoption are whether RFID technology can create a value that will justify its investment, and how the RFID value can be measured. All 
the authors agree with the need for an assessment of the investment prior to the implementation of an RFID system, but only a few actually have proposed models for the analysis of the costs and the benefits (Ustundag \& Tanyas, 2008). It has already been pointed out that none of the models encountered is effective and comprehensive for our purposes, but it is important in this phase to shortly present them, highlighting how authors took inspiration from them in other to present their proposal.

Some authors (Kim \& Sonho, 2009) suggested to consider both the costs derived from the infrastructure implementation than the changes of the logistics processes, taking into account some system inefficiencies. On the other hand, benefits are calculated as the product of the actual sales and a multiplier related to the improvements both at an operational level than in the increase of customer satisfaction and loyalty. This way it is possible to calculate the advantages and disadvantages of the investment. This method, however, presents some limitations due to the fact that the quantification of benefits is based on assumptions and feelings, which are not deterministic, but uncertain. Consequently, those information cannot be used in the development of a qualitative instrument, like a ROI tool. Another study (Ustundag \& Tanyas, 2008) presents a fairly comprehensive model for the identification of the operating cost components, suggesting an interesting method describing the costs of the various logistics processes. This tool estimates the total costs as the sum of all items used at an operational level, which are affected by the introduction of the RFID technology. Through the simulation, it is possible to calculate the costs of lack of sales, costs due to theft, the costs of inventory, orders and employment and obtain the benefits achievable through an RFID system as a variation of the values of total costs.

Some studies have attempted to build models of evaluation of RFID systems by combining different methods of analysis. Doerr et al. (2006) proposes a hybrid methodology for the assessment of costs and benefits of an investment in RFID, by a combination of a multi criterion evaluating qualitative factors, and a Monte Carlo simulation analyzing the expected financial factors. Another example of this approach is provided by Ustundag et al. (2010). In this paper the authors propose a mathematical model for the economic analysis of investment based on the technology's implementation costs and measurement of benefits, in terms of cost reduction and value creation by the RFID technology. In this model, the authors propose the assessment of the Net Present Value (NPV) of the investment through the Monte Carlo simulation. In this framework, at the same time, all the elements that contribute to the total benefits are calculated by taking into account the variable rate of growth in customer demand, which is estimated by a model based on fuzzy logic.

While the authors cited so far determine the benefits with several methods carried out before the introduction of the technology, in most cases the advantages have been originated from the differential calculus before and after implementation.

Veeramani et al. (2008) presents a model for the quantification of five types of benefits that can be obtained: lower operating costs, increased revenues, reduced overhead costs, reduced capital cost of capital and reduction of lead times. All these advantages are analyzed in detail and for each one the author presents mathematical 
formulas in order to calculate the value of these benefits prior and after the RFID implementation. In authors' opinion, although the models presented in this article are very detailed and thorough, the difficulty to find the enormous amount of data needed is certainly a limit to their application.

Going forward, De Kok et al. (2008) propose a model where the benefits are calculated in terms of costs expected by the savings, with and without the RFID technology. In this study, an analytical model that calculate the break-even price of an RFID tag has been presented, indicating that these break-even prices are closely related to the product value, and to the presence of shrinkage (theft or loss of property) before and after the implementation of RFID.

The temporal scale taken into account with the several approaches encountered in literature represents an important issue too. Some models are running a simplistic quantification statistical analysis, while others analyze several cash flows hypothesis generated in the course of several years, going, in some cases, to update such data, thus obtaining a more complete reference. The investment in RFID assessments carried out by the "classical" analysis of the Net Present Value (NPV), of the PBP, the ROI and Internal Rate of Return (IRR) belong to this category. These methods have, however, the limit to consider only the cash flows related to fixed and variable costs, but do not include costs associated with the loss of profitability, such as opportunity costs (Kim \& Sohn, 2008).

Moving to the more recent papers, Bottani \& Rizzi (2008) quantitatively evaluated the impact of RFID and EPC system on the main processes of the supply chain of fast moving consumer goods (FMCG). Using the information gathered through interviews with major companies from different industries, a supply chain "representative" has been assumed and a feasibility analysis has been subsequently conducted. The study has been carried out by distinguishing the case and pallet-level case-level tagging and by determining the value of RFID and EPC implementation. The annual cash flows have also been considered, quantifying the end result NPV, PBP, IRR and ROI over a period of 5 years and an interest rate of $5 \%$, for the distribution center of the manufacturer and for the distributor and the retailer.

The results of the feasibility study have shown that the implementation of RFID systems and the EPC has not yet provided profitability for all the cases examined. Although the adoption of RFID tags on pallets with the application of revenue is positive for all players in the supply chain, case-level tagging has produced, in some scenarios, negative economic performance.

The ROI analysis conducted by Sarac et al. (2008), unlike the previous case, is based on a simulation approach, which has been widely used in this research field also by other authors, as shown by the analysis of the literature. In particular, in this study, is placed attention on the possibility of obtaining different types of RFID systems, through a combination of different types of tags, readers, frequency and levels of tagging, etc. As the costs and potential profits of each system differ significantly, at different time horizons, five different scenarios of a supply chain consisting of a producer, distributor and retailer have been simulated, also evaluating their ROI. 
Lee \& Byoung-Chan (2010) propose a study to provide a normative investment evaluation model that integrates intangible benefits into the objective function, investigating the relationships between model input parameters (e.g., demand, RFID cost functions), decision variables (e.g., RFID investment level) and result variables (e.g., total cost savings and benefits). The approach is based on the classic economic order quantity (EOQ): while the EOQ model consists of setup cost and inventory holding costs, the proposed model considers three unique RFID investment factors of ordering efficiency, Just-In-Time (JIT) efficiency, and operating efficiency and derives optimal investment levels related to these efficiencies.

Finally, Bottani et al. (2009), reports a selection of case studies, conducted by a panel of experts, aims to evaluate the impact of RFID on the logistics processes in the fashion supply chain. The analysis has involved both distribution centers (DC) than retail stores (RS), located in Italy, belonging to the chain of seven companies in the fashion industry: through visits, interviews and questionnaires the data necessary to delineate the AS IS mapping process have been collected, followed by the phase of reengineering (TO BE), with the use of RFID technology for different activities.

After calculating the average costs and benefits generated by the use of technology for each process investigated in the DC and RS, NPV, PBP, IRR and ROI have been calculated over a period of 5 years (interest rate 5\%), using a model developed in MS Excel $^{\circledR}$. Three main factors have affected the profitability of the investment:

- AS IS processes of DC and RS: the combination of different scenarios for the DC and then the RS identifies about 2 million possible configurations of supply chain: among them two scenarios corresponding to best and worst configurations were analyzed in more detail.

- the structure of the supply chain (in particular the number of RS)

- the increase in turnover (TI) in RS due to the implementation of RFID: it identifies four possible values $0 \%, 2.5 \%, 5 \%, 7.5 \%$, although in other studies (O'Connor, 2008) promises an increase in turnover of $15 \%$.

The results are reported and presented from different angles, highlighting the different importance of the factors mentioned above. In general, the implementation of RFID systems is in most cases profitable only analyzing the whole supply chain. In the break-even analysis, according to different parameters, the influence due to the cost of the tag is also investigated. Finally, the NPV, PBP, IRR, ROI are reported as a function of the percentage increase in sales. In the worst case, the investment is profitable if the low turnover increase results to be less than or equal to $5 \%$. In the best configuration, instead, the investment is always profitable in the period of 5 years in question, regardless of the increase in sales. Finally, it is possible to observe that, if the increased revenue is greater than or equal to $7.5 \%$, the implementation of RFID is always profitable, regardless of the configuration of the DC and RS AS IS.

Most of the papers previously cited describe a tool, often developed using MS Excel $^{\circledR}$, for the calculation of the costs associated with implementation of the RFID 


\begin{tabular}{|c|c|c|c|c|}
\hline Paper & Year & Industry & Proposed model & Limitations \\
\hline Doerr et al. & 2006 & Fashion & $\begin{array}{l}\text { Hybrid method composed } \\
\text { of qualitative factors and } \\
\text { Monte Carlo simulation }\end{array}$ & $\begin{array}{l}\text { The model is very complex and } \\
\text { difficult to apply in real } \\
\text { context }\end{array}$ \\
\hline $\begin{array}{l}\text { Ustundag \& } \\
\text { Tanyas }\end{array}$ & 2008 & Fashion & Quantitative: ROI & $\begin{array}{l}\text { Benefits and costs are } \\
\text { simulated and not collected }\end{array}$ \\
\hline Veeramani et al. & 2008 & Fashion & Quantitative: ROI & $\begin{array}{l}\text { Very detailed approach, with } \\
\text { some difficult in the } \\
\text { estimating of each value } \\
\text { needed }\end{array}$ \\
\hline de Kok et al. & 2008 & Fashion & Quantitative: ROI & Very detailed model \\
\hline Kim \& Sohn & 2008 & Fashion & Quantitative: ROI & $\begin{array}{l}\text { Do not include costs related to } \\
\text { loss of profitability such as } \\
\text { opportunity costs }\end{array}$ \\
\hline Bottani \& Rizzi & 2008 & FMCG & Quantitative: ROI & Single industry specific \\
\hline Sarac et al. & 2008 & & Qualitative & Approach based on simulation \\
\hline Kim \& Sonho & 2009 & Fashion & $\begin{array}{l}\text { Quantitative: Multiplier } \\
\text { evaluation }\end{array}$ & $\begin{array}{l}\text { Benefits quantification are } \\
\text { estimated and not evaluated }\end{array}$ \\
\hline Bottani et al. & 2009 & Fashion & $\begin{array}{l}\text { Qualitative and qualitative: } \\
\text { NPV, PBP, IRR, ROI }\end{array}$ & $\begin{array}{l}\text { Case studies conducted by a } \\
\text { panel of experts }\end{array}$ \\
\hline Ustundag et al. & 2010 & Fashion & $\begin{array}{l}\text { Hybrid approach composed } \\
\text { of NPV Monte Carlo } \\
\text { simulation }\end{array}$ & $\begin{array}{l}\text { The model is very complex and } \\
\text { difficult to apply in real } \\
\text { context }\end{array}$ \\
\hline $\begin{array}{l}\text { Lee \& } \\
\text { Byoung-Chan }\end{array}$ & 2010 & Fashion & Qualitative & $\begin{array}{l}\text { The proposed model consider } \\
\text { only three RFID investment } \\
\text { factors }\end{array}$ \\
\hline
\end{tabular}

technology and, more generally, for the economic assessment. One of the described tool has been developed by IBM and Accenture. The software allows to customize the ROI calculation, taking into account the company activity (manufacturer, distributor, retailer, etc.), the level of traceability required (pallets, crates or items) and the expected benefits (Angeles, 2005). This tool has been used both by Veeramani et al. (2008) than Bottani et al. (2009).

\section{Research methodology}

Starting from the literature review presented above, this study presents a model based research which aims is to evaluate investments in RFID technology applied for logistics performances optimization. In order to validate the empirical research, a case study has been performed, highlighting the industrial impacts of the proposed model and adding value to the research.

In order to understand the impacts of the RFID technologies, a cost model has been provided. This research proposes a new tool useful for assessing RFID profitability in the fashion supply chain. It takes a holistic look at RFID technology and its possibilities of implementation by various users. As such, it follows recommendations from 
Gunasekaran et al. (2006) that IT project evaluations should not only focus on a strict cost benefit approach, but also take into account strategic issues such as customer service and quality.

The model based research has been connected to an action research in order to achieve a validation and to test the impacts on the industry considered. The action research uses a scientific approach to study the resolution of important organizational issues together with those who experience these issues directly (Coughlan \& Coghlan, 2002). It works through a cycle that comprises a pre-step to understand context and purpose and then, the diagnosing and the taking action steps.

Coming to the present study, the pre-step has consisted on the understanding of the context of action and on the establishment of collaborative relationships. In fact, the action research focuses on a RFID technology deployment for the fashion industry: the managers of the company considered have initially supported the definition of the supply chain. The manufacturing sites and distribution center taken into account are located in Italy. In a preliminary meeting several employees, directly reporting to the management and involved in the key business function where RFDI technology implementation can achieve greater impacts, were asked to suggest which echelons of the supply chain should be considered to assess the impact of RFID. It was agreed that the supply chain to be considered should start from the manufacturing processes, where tags are applied, to each SKU (item-level) and should include the Distribution Center (DC) of the company. Hence in this study we neglected the impact of RFID on Retail Stores (RS), because of the difficulties encountered in managing tags at stores, given the fact that the company did not have directly operated stores (DOS) when the research has been conducted.

The diagnosing step has occurred through the data collection and analysis. The data collection phase has been performed by means of questionnaires in order to collect qualitative and quantitative information regarding the processes performed at the manufacturing sites and at the DC. Site visit, current processes mapping and data collection took approximately 6 months. Qualitative information have been, mainly, used to redesign logistic processes in order to achieve better performances due to the presence of RFId tags on single items. Quantitative data, as already said, have been collected, after the phase of processes redesign, and put into the ROI evaluation tool in order to understand benefits.

During the planning step, the actions which need to be taken have been individuated. Concerning the manufacturing sites, the processes investigated (1) item tagging and (2) inventory management; regarding the DC, the following processes have been mapped: (1) receiving, (2) storage, (3) inventory management, (4) picking and sorting, (5) stock movement, (6) packing and marking, (7) shipping, (8) reverse logistics. For ethical purposes, employees involved in the case study, as well as in information gathering, were made aware of the study. They were clearly briefed on the fact that the nature of the time study was not to measure their individual performance, but rather to obtain data on overall logistic process efficiency on an aggregated level and that this study will not impact on their performance evaluation. 


\section{Development of research model}

The proposed model, based on the Return of an Investment (ROI) evaluation in RFID technology, has been developed following three steps:

- Evaluation of the costs derived from the RFID technology application.

- Understanding the impact of the technology on the Supply Chain, in terms of process redesign and their improvements.

- Quantitative evaluation of the benefits.

In order to achieve these objectives, the assessment model has been divided into three main sub-systems:

1. Costs evaluation for the infrastructure required in order to implement RFID solution,

2. Analysis of benefits deriving from the RFID technology introduction,

3. Analysis of benefits deriving from the increase of effectiveness and deriving from other intangible benefits linked to the previous one.

The evaluation of costs and benefits must be linked to the real structure of the supply chain considered both in terms of people, information and material flows. Even if the proposed model has to be easy to use and flexible enough to include different domains, it has to be suitable to the fashion industry.

The scenario used as a reference for the evaluation of relevant costs and benefits associated with the introduction of RFID technology in the supply chain is characterized by the use of radio-frequency communication (Wi-Fi) in the DC, with the objective to improve the logistics performances. In detail, the following processes have been considered:

1. "Receiving": each receiving dock is equipped with an RFID portal/gate where RFID tags of items inside pallets and cases are read.

2. "Putaway": employees as well as forklifts are equipped with RFID enable portable device. By reading tags of items, the system provides the information concerning warehouse location where the product should be stored.

3. "Picking and sorting": using to the same equipment described for the "putaway" process, employees pick up items to be shipped, with the right quantities to fulfil every single order.

4. "Shipping" the area of shipping is equipped with packing/wrapping stations with RFID antennas. Shipping doors are equipped with RFID portals.

Because of the fact that the model is based on the application of EPC labels directly on the item, the following assumptions have been done:

1. RFID tags are also used to identify the storage locations and the gates of receiving / shipping;

2. tags are not disposable, i.e. they cannot be recovered once applied to items; 
3. the forklifts are equipped with a reader and two antennas that allow the automatic recognition of the item and the storage location;

4. employees are equipped with RFID handheld readers to be used for inventory control and for the preparation of the cases/pallets to be shipped.

This way, in the scenario described above, the receiving RFID gate is used in order to check all the products contained in a pallet. A second step of security control is represented by a station, equipped with an RFID reader and two antennas, where employees can check automatically the correctness of their picking. After the picking phase, in the model a packaging/wrapping station equipped with RFID gate is hypothesized in order to check the units and associate them to the pallet.

Further assumptions used in the model, although not mandatory for its application, are:

1. An RFID station working with an accuracy of tags reading of $99 \%$.

2. Savings related to the possibility to reallocate employees previously dedicated to logistics activities, related to the process described above.

3. No recovery of used tag.

4. Usage of pallet as loading unit of the warehouse (from here UDC).

5. The availability of a WMS (Warehouse Management System) in the warehouse. In particular, the WMS is used to identify the location of the products and to schedule the task of picking in order to optimize picking routes.

Going further into the detail of the model, the Total Cost of Ownership (TCO) is used in order to evaluate the return of the investment. The TCO is defined, in general, as the total cost of purchase, operation, management and maintenance of an asset within its life cycle. In the next paragraphs, the costs of the implementation will be described in detail, step by step.

\subsection{Costs}

The costs of the RFID implementation have been classified according to four sequential activities:

1. Elaboration: the preliminary stages of analysis "as is", concept design "to be" and defining the roadmap

2. Infrastructure Construction Cost: hardware, software and resources, both internal and external, necessary for the construction of the system infrastructure

3. Transition \& Go-Live: e.g. the costs relevant to the various laboratory tests, the "site survey", the necessary training and warm-up system

4. Total Operating Cost: e.g. "Operation \& Maintenance" all the various operating costs and operating currents. 


\subsubsection{Elaboration}

In the Elaboration phase a detailed analysis of the requirements has been developed. In this phase the RFID architecture and the performances to be reached in terms of efficiency and effectiveness are selected.

The cost of this phase is strongly influenced by the level of know how on the RFID technology in the company. The greater is the knowledge of RFID the easier is to find out the processes that can be improved and to identify the right technology to implement.

\subsubsection{Infrastructure construction cost}

The totals investment costs related to the hardware infrastructure are divided into five categories.

- Shipping and receiving doors at warehouse: for each door, an RFID portal has been hypnotized, assuming that each single item inside the case has been labelled with an RFID tag.

- Forklift: all the forklifts used for moving pallets or case in the warehouse are equipped with readers and antennas in order to allow identification of items, the door for receipt / shipment and storage locations

- Packaging/Wrapping station: a RFID system enables items' identification and their association to the EPC code of pallet.

- Handheld devices: handheld devices have to be used for the inventory control.

- Tags printers: in case the company chooses the option to print and serialize the RFID in house these elements are required. As for the previous case, label printers may be already present, in this case care must be taken to evaluate only the cost of the RFID module.

In addition to the hardware, a software application (middleware) to manage the data from the RFID reader and achieve integration between the hardware components and the existing technology is required.

In addition to these features the middleware must allow the correct configuration of each element of the RFID system and has to encourage the development of architecture in the various nodes of the supply chain.

\subsubsection{Transition \& Go-Live}

Transition \& Go-Live refers to the activity running from the project start-up to the time when the installation is completed. The costs taken into account during this time range are:

- Product testing and application/ insertion of the test tag

- System and integration test

- Employees training 


\subsubsection{Total operative cost}

This component represents the real kernel of the proposed model. In this section we analyze the major changes introduced adopting the RFId technology, evaluating the costs that arise in managing processes along the Supply Chain and in the DC.

In order to evaluate such costs we need to identify what are the processes and other areas or activities that undergo major (or less) changes once completed the RFID system integration. After that, we need to highlight the parameters characterizing the processes thus defining the input data that must be collected. In this way it is possible to evaluate the costs associated with the execution of logistics operations in accordance with the assumptions made.

As above explained there are several cost categories that change or emerge with the implementation of RFID: some costs focus on the change of performances due to the influence of the new technology, while others focus on the management of new introduced assets. The categories of cost we took into consideration, evaluating the Total Operative Cost are:

Logistic processes: e.g. the costs required to manage items by using an RFID system (according to Kim \& Sohn, 2009). These costs refer to the resource usage in warehouse operations, that we assume to be reduced by RFID, together with costs for the tagging of items.

Inventory (or Holding): refers to the associated costs of storing inventory or assets from the moment the company receives them from supplier until the instant they are delivered to customers. There are several different types of holding costs that are likely to be applied to the maintenance of any type of inventory.

Ordering: the costs required to manage the ordering activities. It depends on the amount of the items to be ordered (or the annual number of orders) and thus on the accuracy of the inventory level which can be strongly improved by the RFID system.

Count: costs related to annual inventory counts. Such costs depend on the annual number of counts, the number of employees and the time required for each count. We assume that such costs can be reduced because of RFID in several ways, such as greater accuracy and faster operations.

Reverse Logistics: according to literature, this category of costs refers to the management and handling of returns, from the point of recovery or consumer at the point of origin. From the point of view of a fashion company, we assume that such costs are mostly related to managing wrong deliveries (e.g. items sent to wrong customers or in mistaken amount, ... ) as well as re-work activities on not acceptable products.

Maintenance: this category refers to the annual costs the company has to incur to manage different assets essential for the right implementation of an RFID system.

Power consumption: is the energy cost that the company needs to incur concerning the operation of the RFID system.

EPC Global subscription. This cost refers to the annual subscription fee that a company has to pay to be a member of the EPCGlobal organization to achieve worldwide adoption and standardization of Electronic Product Code (EPC) technology. The cost has been estimated basing on the available commercial sources. 
All these costs have been estimated according to the Activity Based Costing approach, assessing the use of each resource by different activities. The driver used is the time each activity requires, because this value seems to be the more suitable for the evaluation of such operations, as specified in the literature: the amount of resources is measured in terms of time availability, thus distinguishing between used and not -used (Varila, Suomala et al., 2007). The assessment also considers a medium-long term point of view, therefore all costs will be considered annually.

Once more it is important to emphasize that cost variations for all the categories listed before, can be strongly influenced by the changes that may occur after implementing the RFID technology concerning the flows of items (in comparison to the ones that the company has achieved before).

The variable which better represents these changes is the inventory level. There is a large variety of Supply Chain management literature concerning inventory management models: all these models require the presence of a warehouse where items/products are stored and some rules suggesting "when" and "how" to place a new order.

Among these models, the Periodic Order Quantity (POQ) has been chosen. The decision to adopt such a model comes from the fact that the fashion companies production planning process is usually is executed at regular intervals, tipically every two weeks.

Production orders differ by quantity and composition, having to match several requirements, mostly, coming from the market. As known, the total amount of item to be produced derives from the merchandise plan, which is developed generally 3-6 months before the starting of production, and from the data coming from forecasts concerning the so-called carryover. Companies spread these data along a given time window placing production orders at regular time with different quantities trying to follow, as much as possible, the pattern of demand.

This way, the POQ model better approximates the dynamics of RFID applications, fitting to the structure of the cost model previously described. Indeed, this method results to be easier and less expensive than others and allows the reordering for multiple products at the same time.

Basically the POQ method aims to keep the inventory level (i.e the sum of the items lying in stock and items already reordered) close to a target level (TL) to be computed on the occasion of reorders occurring at regular time intervals. Thus the quantity to be reordered is variable from time to time and is then given by the difference between the target value and the current inventory level.

In the case of fashion companies we can assume that target level can be different at different time interval (i-period), having to follow, as above explained, the demand pattern, and the current inventory level $\left(\mathrm{I}_{\mathrm{i}}\right)$ can represent the amount of SKU both in stock at the distribuition center (DC) of the company,both in stock (i.e. not sold) inside the shops (retail). Without a loss of generality, we can also assume the inventory level to be null in case of capsule collection when fashion companies decide not to have any stock for given products. 
Throughout this paper we use two different notations, depending on which scenario is taken into account. When formula refers to the scenario with RFID implementation the "RFID" subscript is added, otherwise we use the " $\varnothing$ " subscript.

When the formula remains the same for both scenarios we add the "RFID / Ø" subscript.

As well known, the inventory target level at a given time interval $I\left(T L_{i}\right)$ depends on the lead time of supplier $\left(T_{S}\right)$, the time interval between two orders $\left(I_{r}\right)$ and the estimated demand per time unit referred to the $i$-period $\left(d_{i}\right)$ and is calculated as:

$$
T L_{i}=d_{i} *\left(T_{s}+I_{r}\right)
$$

Uncertainties in supply chain, logistic processes and demand commit companies to add safety stocks to the target level. As known, Safety Stocks depends on the stability of demand or consumption (where $\sigma_{c}$ indicates the standard deviation), on the reliability of the supply chain system (expressed by the supplier lead time, $T_{S}$ ) and on the service level provided to customers, which is represented by the coefficient $k$ indicating the value of the standardized variable which corresponds to a cumulative probability value equal to the service level desired:

$$
S S=\sigma_{c} \cdot k \cdot \sqrt{\left(T_{S}+I_{r}\right)}
$$

In order to measure performance losses, mostly due to wrong logistics processes, the following variables have been introduced:

- Misplacement rate: $[\alpha]$

- Damaged rate: $[\beta]$

- Incomplete shipment rate: $[\delta]$

- Theft rate: $[\gamma]$

- Return rate: $[R R]$

In this paper we assume that such losses can be incorporated in the safety stocks evaluation according to the following formula, where we put the " $\varnothing$ " subscript thus referring to the not-RFId scenario.

$$
S S_{\emptyset}=S S \cdot(\alpha+\beta+\gamma+\delta)_{\emptyset}
$$

Implementing an RFID system will improve the performances of all logistics processes, increasing the Supply Chain visibility, thus reducing losses and uncertainty, in formula:

$$
S S_{R F I D}=S S \cdot(\alpha+\beta+\gamma+\delta)_{R F I D}=S S_{\emptyset} \cdot \frac{(\gamma+\delta+\beta+\alpha)_{R F I D}}{(\gamma+\delta+\beta+\alpha)_{\emptyset}}
$$

In order to evaluate the Total Operative Cost we introduce the following nomenclature: 
- The level of initial inventory, that can be calculated by the inventory of the warehouse at the end of the previous period $\left[I_{0}\right]$.

- Total item demand $\left[D_{i}\right]$ for the $i$-period.

- Standard deviation $\sigma_{s}$ of the Lead Time of supplier.

- Number of orders [\#_ord ${ }_{\mathrm{i}}$ ] during the $i$-period.

- Average number of lines order per each order [\#_righ /ord]

The company target levels including safety stocks can be written as

$$
\begin{gathered}
T L_{(i, R F I D)}=T L_{i}+S S_{R F I D} \\
T L_{(i, \emptyset)}=T L_{i}+S S_{\emptyset}
\end{gathered}
$$

Following the POQ order policy, the amount of items to be ordered any $i$-period from the supplier is given by the difference between the target level required and the current inventory level (at the $i-1$ time interval), in formulas:

$$
\begin{gathered}
Q_{(i, R F I D)}=T L_{(i, R F I D)}-I_{(i-1, R F I D)} \\
Q_{(i, \emptyset)}=T L_{(i, \emptyset)}-I_{(i-1, \emptyset)}
\end{gathered}
$$

Company items shrinkage, due to logistics inefficiencies (expressed, as already said, by the $[\alpha, \beta, \gamma, \delta]$ parameters) can be assumed to depend on the value of company target level:

$$
\begin{gathered}
D_{S, R F I D}=T L_{i} \cdot(\alpha+\beta+\gamma+\delta)_{R F I D} \\
D_{S, \emptyset}=T L_{i} \cdot(\alpha+\beta+\gamma+\delta)_{\emptyset}
\end{gathered}
$$

The effective demand, $\left[D_{\text {effective_ }} R F I D / \emptyset\right]$, is defined as the sum of two values, one arising from external market (e.g. customers) and one from internal losses (e.g. shrinkage) and will be useful to determine the balance at end of period.

The nomenclature indicating different categories for production costs is:

- Labour hourly cost $(€ / \mathrm{h}),\left[L C_{h}\right]$

- Overhead costs $(€ / \mathrm{h}),\left[C_{o h}\right]$. This costs are allocated according to the Activity Based Approach as stated above.

- Rework cost (€/item) estimated for a single "rework" $[C R]$

- Labour hourly cost $(€ / \mathrm{h})$ for insertion of tags into the product, also known as labelling $\left[c_{l a b}\right]$

- Labour hourly cost $(€ / \mathrm{h})$ for error recovering $\left[c_{\text {err }}\right]$

- Tag unit cost (€/unit) [ctag $]$

- Purchasing cost for each item from the suppliers. This valaue is calculated as a weighted average of items on stock, $(€)\left[c_{i t e m}\right]$

- Holding stock cost (€/item/time unit), $\left[c_{h}\right]$ 
Operating inefficiency can be represents by the following variables:

- Inbound (receiving) error rate: $\left[R E_{i}\right]$

- Outbound (shipping) error rate: $\left[R E_{o}\right]$

- Picking error rate $\left[R E_{p k}\right]$

Time required to perform different warehouse processes, evaluated in seconds and referred to a single item, are expressed by:

- $T_{i}$ : Receiving Time (Input Time)

- $T_{o}$ : Shipping Time (Output Time)

- $T_{p t}$ : Putaway Time

- $T_{p k}$ : Picking Time

- $T_{l a b}$ : Time required for tagging each single product

- $T_{\text {Count }}$ : Total time of inventory, is the product between the annual number of inventories and the time required to complete one.

These variable will be addressed, in the rest of this paper, with the two subscripts, "RFID" or " $\varnothing "$ " indicating whether they are evaluated in the RFID scenario or not.

The evaluation model has also to consider the time required for operations that will not occur (because eliminated or automated) with the introduction of the RFID technology:

- $T_{r}$ : defined "recovery time", time necessary to correct and recover discrepancy in warehouse processes

- $T_{i p t}$ : time to identify the item and its location and update the company information system during the putaway activity

- $T_{i p k}$ : time required to find the item and its location, check the accuracy of picking and update the company information system

- $T_{i o}$ : time used to check the shipping and update the corporate information system

- $T_{i s i a}$ : time required to enter items data in the information system

\subsubsection{Costs model}

The costs evaluation is carried out through a series of formulas which refer to the input data, as shown below.

1. Total Receiving cost:

$$
C_{\text {Receiving }}=\left[\sum \frac{Q_{(i, R F I D)} \cdot T_{i R F I D}}{3600}\right] \cdot L C_{h}
$$

2. Total Putaway cost:

$$
C_{\text {Putaway }}=\left[\sum \frac{Q_{(i, R F I D)} \cdot T_{p t R F I D}}{3600}\right] \cdot L C_{h}
$$


3. Total Picking cost:

$$
C_{\text {Picking }}=\left[\sum \frac{\# \text { ord }_{i} \cdot \# \text { righe } / \text { ord } \cdot T_{\text {pt RFID }}}{3600}\right] \cdot L C_{h}
$$

4. Total Shipping cost: we consider only the "external marked" demand, $D_{i}$. From the shipping point of view company shrinkage must not be taken into account

$$
C_{\text {Shipping }}=\left[\sum \frac{D_{i} \cdot T_{o} R F I D}{3600}\right] \cdot L C_{h}
$$

5. Tag insertion (e.g. tag labelling) cost: this cost category includes both the cost for purchasing $Q_{i, R F I D}$ tags and the cost required for inserting them into each item:

$$
C_{\text {Labelling }}=\left[\sum Q_{(i, R F I D)} \cdot C_{t a g}\right] \cdot T_{l a b} \cdot c_{l a b}
$$

6. Total Count cost:

$$
C_{\text {Count }}=T_{\text {Count }} \cdot L C_{h}
$$

7. Total Holding cost:

$$
C_{\text {Holding }}=\sum_{i}\left[C_{h} \cdot\left(\frac{d_{i} \cdot I_{r}}{2}+S S_{(i, R F I D)}\right)\right]
$$

8. Total Ordering Cost: e.g. the total cost for purchasing $Q_{i, R F I D}$ items from suppliers

$$
C_{\text {Order }}=\sum_{i} C_{i t e m} \cdot Q_{(i, R F I D)}
$$

9. Total Reverse logistics cost, referring to costs for transport, repair or credit to the customer warehousing costs and spare parts:

$$
C_{\text {Reverse }}=\sum_{i}\left(D_{i} \cdot R R \cdot C R\right)
$$

\subsection{Benefits}

The evaluation of the benefits is a more complex process than cost estimation. While it is not particularly difficult to accurately assess savings resulting from the introduction of RFID when its role is clear, namely to automate processes previously manually performed, it is also true that most of the benefits enabled by such kind of investment, playing an organizational role, involve intangible benefits, related more to the quality than to the quantity of work performed.

As known, benefits arising from implementing a new IT solution can be divided into three levels: strategic, tactical and operative. 
The benefits of the first level (strategic) are the most difficult to predict and quantify: they are very uncertain and the traditional valuation techniques are ineffective. The benefits of the operational level, are related to the increased efficiency of processes and therefore are easier to identify and to estimate. Finally the benefits of the tactical level are relatively heterogeneous and they may be allocated in an intermediate position regarding the tangibility and quantification: some of them impact in terms of efficiency, the others in terms of effectiveness.

All benefits at the operational level can, by their nature, be classified as tangible and therefore involve improvements in terms of efficiency and are measurable. Analyzing in detail each of the operational activities influenced by RFID, it is important to identify which are the benefits that can be monetized and which ones not directly.

Receiving: the efficiency increases if mainly connected to the automation of the check accuracy for the receiving items and correction of errors, also allowing a reduction of the required process time for a single item and eliminating some operations.

Cost saving due to bar-code labels elimination is defined as follows:

$$
C_{\text {labels }}=\sum_{i}\left(Q_{(i, \emptyset)} \cdot C_{\text {label }}\right)
$$

Labour cost to correct receiving errors (documentation, identification, type and quantity of items) is defined as follows:

$$
C_{\text {Receiving_Err }}=\sum_{i}\left(Q_{(i, \emptyset)} \cdot R E_{i} \cdot T_{r} \cdot C_{\text {err }}\right)
$$

Putaway: Labour cost to identify the item and its location and update the company information system:

$$
C_{\text {Putaway }}=\sum_{i}\left(Q_{(i, \emptyset)} \cdot T_{p t} \cdot L C_{h}\right)
$$

Picking: the activity of order picking is one of the most influenced by the RFID technology. This benefit is related to the ability to automatically identify picked products during operation.

RFID allows to save labour cost related to errors of picking (documentation, identification, type and quantity of items):

$$
C_{\text {Picking_Err }}=\sum_{i}\left\lfloor\left(\#_{-} \text {ord }_{i} \cdot \# \text { rig } / \text { ord }\right) \cdot R E_{p k} \cdot T_{r} \cdot C_{\text {err }}\right\rfloor
$$

Lost time for misplaced items:

$$
C_{\text {Misplacement }}=\sum_{i}\left[\left(\# \_o r d_{i} \cdot \# \text { rig } / \text { ord }\right) \cdot \alpha \cdot C_{\text {err }}\right]
$$


Labor cost to check the picking and update the company information system:

$$
C_{\text {Picking_Update }}=\sum_{i}\left\lfloor\left(\# \_ \text {ord } d_{i} \cdot \# \text { rig } / \text { ord }\right) \cdot T_{i p k} \cdot L C_{h}\right\rfloor
$$

Shipping: Cost of the use of workers to correct the errors in the shipment (documentation, identification, type and quantity of items, time lost to misplaced item):

$$
C_{\text {Shipping_Err }}=\sum_{i}\left[D_{i} \cdot R E_{o} \cdot T_{r} \cdot C_{\text {err }}\right]
$$

Cost of the use of workers to control the operation of shipping and for updating the information system:

$$
C_{\text {Shippin__Update }}=\sum_{i}\left(D_{i} \cdot T_{i o} \cdot L C_{h}\right)
$$

Costs related to inventories:

$$
C_{\text {Count }}=T_{\text {Count }, \emptyset} \cdot L C_{h}
$$

Depending on the data entered, the ROI tool allows the calculation of costs and benefits relating to the hypothesized scenario. This analysis defines the main indicators of economic feasibility for the investment, such as the net present value (NPV), the internal discount rate (IRR) and the payback period (PBP).

\section{Model application}

In order to applicate the proposed model, the implementation of the RFId technology has been evaluated into an Italian company, named Fashion \& Co. The company works in the luxury fashion industry, producing leather goods, including Hand Bags (HB) and Small Leather Goods (SLG) (e.g. wallet). The company is located in Florence and production is mainly outsourced to local suppliers. The project has involved the Fashion \& Co. company and its entire supply chain, because of the fact that RFId tags are inserted and linked to items during the production process by the suppliers themselves.

The model has been applied analyzing the introduction of RFId technology in two families of leather products of the Fashion \& Co. company. In order to fill the model, some assumptions have been done on the demand and on the infrastructure costs.

Regarding the demand, and consequently the inbound and outbound flows at the DC, a ratio between leather bag and small leather goods of 67/33 has been hypothesized. This assumption derives from the historical data of the company in the previous years. A period of eleven months has been taken into consideration. Tables 13 and 14 in the appendix of the paper report a summary of inbound and outbound flows observed at the DC.

The DC has been equipped by receiving and shipping areas both equipped with RFID gates. Moreover, for the allocation and picking phases twenty handheld RFID 
Table 1

Input data of the RFID tool

\begin{tabular}{lcc}
\hline Time [s]: & Without RFId & With RFId \\
\hline$T_{i}$ & 24,00 & 1,30 \\
$T_{o}$ & 14,40 & 14,40 \\
$T_{p t}$ & 28,80 & 28,80 \\
$T_{p k}$ & 36,00 & 9,00 \\
$T_{\text {Count }}(\mathrm{h})$ & 160 & 6,4 \\
$T_{r}$ & 300 & - \\
$T_{i p t}$ & 0 & - \\
$T_{\text {isia }}$ & 9,6 & - \\
$T_{i o}$ & 0 & - \\
\hline
\end{tabular}

devices have been installed. In order to permit to the handheld RFID devices to work, a Wi-Fi network has been installed on the whole DC. Eight access point were installed and two thousand meters of Ethernet cable were laid.

Regarding the development of the software needed in order to integrate the RFID technology with the Warehouse Management System (WMS) of the company, a "Point-to-Point" tool capable to integrate the feature of the reader with the software of the Fashion \& CO company has been developed. This choice avoided the development of a middleware, reducing the cost of integration between the WMS and reader.

Regarding the operation costs, the SS has been assumed equal in both scenarios. This way, the coefficients Misplacement rate $[\alpha]$, Damaged rate $[\beta]$, Incomplete shipment rate: $[\delta]$, Theft rate $[\gamma]$ and Return rate $[R R]$ are assumed equal to zero. As a consequence the formula (2) and (3) lead to the same result, which is obviously conservative. Moreover (5a) is equal to (5b).

Moving to the evaluation of the cost model, in order to calculate the formula (6), (7), (8), (9), (10), (11), (12), (13) and (14) the parameters reported in Table 1 have been determined during the observation period.

Regarding the benefits due to the RFID technology, the formula (15), (16), (17), (18), (19), (20), (21), (22) and (23) are calculated with the data reported in Table 13 and Table 14. In the case described above the value different from zero are (16), (20) and (23). In particular, (16) is equal to -300 , (19) to $-9,6$ and (23) to $(-160+6,4)$.

Based on the scenario described above, the model has been applied and all the costs calculated. The results are reported in the appendix of the paper (Tables 3, 4, 5, 6, 7, $8,9,10)$.

Once the costs have been evaluated, using the data providing from demand described above, the P\&L of the investment have been calculated. The results of this analysis are reported in the Tables 11 and 12, in order to compare the solution with the RFID technology and the traditional one.

Last, the ROI evaluation has been done and reported in Table 1, where the indicators IRR, PBP and NPV are indicated. 
Table 2

Prospect of the economic indicators of the investments

\begin{tabular}{|c|c|c|c|c|c|c|}
\hline$\underline{\text { YEAR }}$ & 0 & 1 & 2 & 3 & 4 & 5 \\
\hline NCF (RFID) & -160187 & 3186996 & -625218 & -510652 & -528273 & -1549341 \\
\hline $\mathrm{NCF}(\varnothing)$ & 0 & 3082150 & -845407 & -753853 & -753853 & -1935258 \\
\hline NCF (RFID- $\varnothing)$ & -160187 & 104846 & 220189 & 243200 & 225580 & 385917 \\
\hline DELTA LCF & -160187 & 242172 & 243200 & 243200 & 225580 & 225580 \\
\hline Delta_NWC(RFID) & & -3703199 & 114566 & 0 & 0 & 1021068 \\
\hline Delta_NWC $(\varnothing)$ & & -3840525 & 91554 & 0 & 0 & 1181406 \\
\hline Delta_NWC(RFID- Ø) & & -137326 & -23011 & 0 & 0 & 160337 \\
\hline $\begin{array}{l}\text { Delta CF + Delta_NWC(RFID- } \varnothing) \\
=\mathrm{NCF}\end{array}$ & -160187 & 104846 & 220189 & 243200 & 225580 & 385917 \\
\hline $\mathrm{DCF}$ & -160187 & 90967 & 165754 & 158842 & 127831 & 189742 \\
\hline WACC & $15,26 \%$ & & & & & \\
\hline NPV & 572947 & & & & & \\
\hline PBP (days) & 456 & & & & & \\
\hline IRR & $2,12 \%$ & & & & & \\
\hline
\end{tabular}

\section{Conclusion}

The importance of RFID technology is gradually growing and it is becoming more and more popular in many industries. The apparel and fashion fields are among the leading sectors driving this adoption, due to the fact that RFID technology can help industries to achieve benefits along the whole supply chain.

In this paper we present a practical tool for calculating expected profitability from a RFID item-level tagging deployment in the apparel supply chain. Authors explored the major costs arising when implementing an RFID base solution as well as the major benefits gained.

Through this paper, authors are proposing a cost model that can be used as an alternative to traditional assessment techniques. As introduced in the Section 2.4, in the literature there are several tools which goal is to evaluate investments in RFId technologies in the fashion industry. At the same time, none of them seem to be applicable to real context, because of the complexity of the model or because of the approach proposed. In authors opinion, the tool presented in this paper seems to be effective in clarifying, in relation to each phase of the entire life cycle of the solution, all the elements of cost arising in implementing and managing an RFID system. This way, the main contribute of this research resides in the model's ease of use, quickness and effectiveness, grossly defining the economical expectations of an RFID investment; given the difficulties in defining precise figures, the study could support the investment choices.

Authors tried to create an accounting system extremely useful to help in better addressing purchasing decisions, considering the total economic impact of each choice throughout the duration of its life cycle. Indeed, in addition to this aspect, it must be stressed that the proposed model refers to the entire cost of implementation 
and not just to the buying phase, referring also to the organizational redesign and Business Process Reengineering.

Some limitations of the study should also be mentioned. First, the results presented are always based on the assumption of a complete installation of RFID, i.e. it is supposed that RFID technology is either exploited to manage all processes of DC or it is deployed at all sites composing the supply chain investigated. Conversely, different scenarios, considering a partial implementation of RFID technology, were not examined in detail in the present study. As highlighted in the previous section, our findings allow to derive some indications concerning the feasibility of a partial implementation of RFID technology; nonetheless, further researches are required to fully examine this point. Second, our study is based on a specific market field, namely the fashion industry. As the input data were derived from just this particular industry, and the processes investigated strictly refer to this context, results presented could not be generalized to other market fields. Further research activities are thus required to investigate the economic impact of RFID technology in different contexts. Quantitative results provided in this paper were obtained by means of real data gathered on a pilot study run by a fashion company in Italy. A future activity will be the application of another cost model to the same company, in order to evaluate the differences among the proposed cost model and the others, in terms of accuracy and reliability.

The study contributes to the existing knowledge by demonstrating and quantifying the economic benefits of RFID implementation in the fashion supply chain. The originality of the paper can thus be found in the validation of theoretical assumptions thanks to the results of an in-field implementation in apparel supply chain. Moreover, thanks to the study, managers operating in the fashion industry can achieve an useful benchmark when pondering the implementation of RFID technology inside a company or on a whole supply chain. For practitioners, the paper offers a thorough insight on how RFID technology could be deployed to increase the likelihood of a successful implementation in the fashion supply chain.

\section{References}

Angeles, R. (2005). RFID technologies: Supply-chain applications and implementation issues. Information Systems Management, 22, 51-65.

Attaran, M. (2010). Strategic implications of RFID implementations in the retail industry supply chain. International Journal of RF Technologies: Research and Application, 2, 155-171.

Bandinelli, R., Rinaldi, R., Rossi, M., \& Terzi, S. (2013). New product development in the fashion industry: An empirical investigation of Italian firms. International Journal of Engineering Business Management, 5, 88-97, ISSN: 1847-9790. doi: 10.5772/56841.

Bange, V. (2006). Putting RFID in writing. Supply Management, 11(2), 34-46.

Bose, I., \& Pal, R. (2005). Auto-ID: Managing anything, anywhere, anytime in the supply chain. Соттиnications of the ACM, 48(8), 101-106.

Bottani, E., \& Rizzi, A. (2008). Economical assessment of the impact of RFID technology and EPC system on the fast moving consumer goods supply chain. International Journal of Production Economics, $112(2), 548-569$. 
Bottani, E., Ferretti G., Montanari R., \& Rizzi, A. (2009). The impact of RFID technology on logistics processes of the fashion industry supply chain. International Journal of RF Technologies: Research and Applications, 1(4), 225-252.

Chen, C., Chen, M, \& Wu, N. (2010). Development of an RFID-based Management System for Fashion Industry. International conference on Service Systems and Service Management, 978-1-4244-64876/10 IEEE.

Choi, S.H., \& Poon C.H. (2008). An RFID-based Anti-counterfeiting System. International Journal of Computer Science, 35, 1-12.

Choy, K.L., Chow, K.H., Moon, K.L., Zeng, X., Lau, H.C.W., \& Chan, F.T.S., et al. (2008). A RFID case-based sample management system for fashion product development. Engineering Applications of Artificial Intelligence, 22(6), 882-896.

Collins, J. (2004). RFID's ROI Top User Concerns. RFID Journal. 28 October 2004, http://www.rfidjournal .com/articles/view?1207, (accessed March 2014).

De Kok, A.G., Van Donselaar, K.H., \& Van Woensel, T. (2008). A break-even analysis of RFID technology for inventory sensitive to shrinkage. International Journal of Production Economics, 112(2), 521-531.

Doerr, K.H., Gates, W.R., \& Mutty, J.E. (2006). A hybrid approach to the valuation of RFID/MEMS technology applied to ordnance inventory. International Journal of Production Economics, 103(2), 726-741.

Fosso-Wamba, S., Lefebvre, L.A., Bendavid, Y., \& Lefebvre, E. (2007). Exploring the impact of RFID technology and the EPC network on mobile B2B e-Commerce. A case study in the retail industry. International Journal of Production Economics, 112(2), 614-629.

Gaukler, G.M., \& Seifert, R.W. (2007). Applications of RFID in supply chains. In Jung, H., Jeong, B., and Chen, F.F. (Eds), Trends in Supply Chain Design and Management: Technologies and Methodologies, Springer, London, pp. 29-48.

Gunasekaran, A., Ngai, E.W.T., \& McGaughey, R.E. (2006). Information technology and systems justification: A review for research and applications. European Journal of Operational Research, 173(3), 957-983.

Hardgrave, B.C., Aloysius, J., \& Goyal, S. (2009). Does RFID improve inventory accuracy? A preliminary analysis. International Journal of RF Technologies: Research and Applications, 1(1), 44-56.

Keating, B., Coltman, T., Fosso-Wamba, S., \& Baker, V. (2010). Unpacking the RFID investment decision. Proceedings of the IEEE, 98(9).

Kim, H.S., \& et Sonh, S.Y. (2009). Cost of ownership for the RFID logistic system applicable to u-city. European Journal of Operational Research, 194, 406-417.

Lee, I., \& Lee, B. (2010). An investment evaluation of supply chain RFID technologies: A normative modeling approach. International Journal of Production Economics, 125, 313-323.

Legnani, E., Cavalieri, S., Pinto, R., \& Dotti, S. (2010). The Potential of RFID Technology in the Textile and Clothing Industry: Opportunities, Requirements and Challenges. Unique Radio Innovation for the 21 st Century, Springer: Berlin/Heidelberg, Germany, pp. 309-329.

Lehtonen, M., Staake, T., Michahelles, F., \& Fleisch, E. (2006). The potential of RFID and NFC in anticounterfeiting. Improving customs processes with RFID and NCF technology to fight illicit trade. Auto-ID Labs White Paper WP-BIZAPP-027.

Loebbecke, C. (2005). RFID technology and applications in the retail supply chain: The early Metro Group pilot. 18th Bled Conference Integration in Action, pp. 1-11.

Loebbecke, C., Palmer, J., \& Huyskens, C. (2006). RFID's potential in the fashion industry a case analysis. Proceedings of the 19th Bled Conference Values, Faculty of Organizational Sciences, University of Maribor, Bled, Slovenia.

Moon, K.L., \& Ngai, E.W.T. (2008). The adoption of RFID in fashion retailing: A business value added framework. Industrial Management Data Systems, 108(5), 596-612.

O'Connor, M. (2009). American Apparel Expands RFID to Additional Stores. RFID journal-article, 4510.

Pisello, T. (2006). Shrinking the supply chain expands the return: The ROI of RFID in the supply chain, Alinean White Paper. 
Rapporto realizzato dal Cedites in collaborazione con Aton S.p.A. (2010). Fashion Grey Market: Come agisce, come combatterlo.

Roh, J.J., Kunnathur, A., \& Tarafdar, M. (2009). Classification of RFID adoption An expected benefits approach. Information \& Managementi, 46, 357-363.

Sarac, A., Absi, N., \& Dauzère-Pérès, S. (2008). A simulation approach to evaluate the impact of introducing RFID technologies in a three-level supply chain. Proceedings of the 2008 Winter Simulation Conference, 978-1-4244-2708-6/08/IEEE

Staake, T., Thiesse, F., \& Fleisch, E. (2005). Extending the EPC Network- The potential of RFID in anti-counterfeiting. AUTO-ID LABS-WP-BIZAPPS-012.

Tajima, M. (2007). Strategic value of RFID in supply chain management. Journal of Purchasing \& Supply Management, 13, 261-273.

Taylor, R.R., Morgan, R.M., \& Morton, A.R. (2003). Efficient versus responsive supply chain choice: An empirical examination of influential factors. Journal of Product Innovation Management, 20(6), $430-443$.

Ustundag, A., \& Tanyas, M. (2009). The impacts of radio frequency identification (RFID) technology on supply chain costs. Transportation Research Part E, Logistics and Transportation Review, 45(1), 29-38.

Ustundag, A., Serdar Kilinc, M., \& Cevikcan, E. (2010). Fuzzy rule-based system for the economic analysis of RFID investments. Expert Systems with Applications, 37, 5300-5306.

Veeramani, D., Tang, J., \& Alfonso Gutierrez, A. (2008). A framework for assessing the value of RFID implementation by tier-one suppliers to major retailers. The Journal of Theoretical and Applied Electronic Commerce Research, 3(1), 55-70.

Veronneau, S., \& Roy, J. (2009). RFID benefits, costs, and possibilities: The economical analysis of RFID deployment in a cruise corporation global service supply chain. International Journal of Production Economics, 10.1016/j.ijpe.2009.06.038.

Wessel, R. (2006). Clothing Manufacturers Invest its ROI in RFID. RFID Journal.

Zahay, D.L., \& Handfield, R.B. (2004). The role of learning and technical capabilities in predicting adoption of B2B technologies. Industrial Marketing Management, 33(7), 627-641.

\section{Appendix}

Table 3

UHF system for one door

\begin{tabular}{lcr}
\hline Components & Quantity & Cost $(€)$ \\
\hline Reader UHF & 1 & 2250 \\
Antenna UHF & 4 & 1040 \\
Motion Sensor & 1 & 400 \\
Traffic light & 1 & 200 \\
Screen & 1 & 200 \\
Installation (h) & 8 & 500 \\
Total & & 4590 \\
\hline
\end{tabular}

Table 4

UHF sistem for forklift

\begin{tabular}{lcr}
\hline Component & Quantity & Cost $(€)$ \\
\hline Reader UHF & 1 & 2000 \\
Antenna UHF & 1 & 400 \\
Wifi terminal & 1 & 1000 \\
Installation (h) & 20 & 1000 \\
Total & & 4400
\end{tabular}


Table 5

UHF sistem film technology station

\begin{tabular}{lcr}
\hline Component & Quantity & Cost $(€)$ \\
\hline Reader UHF & 1 & 2250 \\
UHF antenna & 2 & 520 \\
Screen & 1 & 200 \\
Installation (h) & 16 & 800 \\
Totale & & 3770 \\
\hline
\end{tabular}

Table 6

Total cost hardware for the Fashion \& Co company

\begin{tabular}{|c|c|c|c|}
\hline Hardware element & Quantity & Unit cost $(€)$ & Total cost $(€)$ \\
\hline RFID UHF system for receiving door & 3 & 15000 & 45000 \\
\hline RFID UHF system for shipping door & 2 & 15000 & 30000 \\
\hline UHF Tag KIT for floor location & 0 & 14,2 & 0 \\
\hline UHF Tag for shelf location & 8.850 & 1,9 & 16785,5 \\
\hline UHF System for forklift & 0 & 3700 & 0 \\
\hline Picker & 5 & 3700 & 18500 \\
\hline UHF System Film technology station & 0 & 3770 & 0 \\
\hline UHF RFID Module for handlet & 20 & 750 & 15000 \\
\hline Access Point & 8 & 280 & 2240 \\
\hline Ethernet cable $(€ / \mathrm{m})$ & 2090 & 1,71 & 3573,9 \\
\hline UHF Printer & 0 & 5000 & 0 \\
\hline Total hardware cost & & & 131.000 \\
\hline$\pi+1$ & & & \\
\hline \multicolumn{4}{|c|}{ Total cost of the "Elaboration" phase of Fashion \& Co } \\
\hline Activity & & & Cost $(€)$ \\
\hline \multicolumn{4}{|l|}{ Elaboration } \\
\hline \multicolumn{3}{|c|}{ Awareness (reunion and Team definition) } & 2000 \\
\hline \multicolumn{3}{|c|}{ Technical documents (Process Analysis and BPR) } & 8750 \\
\hline \multicolumn{3}{|l|}{ Supplier Selection } & 0 \\
\hline \multicolumn{3}{|l|}{ Total } & 10750 \\
\hline
\end{tabular}

Table 8

Total cost of the "Infrastructure Construction Cost" of Fashion \& Co

\begin{tabular}{lr}
\hline Components & Cost $(€)$ \\
\hline Infrastructure construction cost & 131100 \\
Hardware & 7200 \\
Software: Integration cost with WMS & 3400 \\
License (handheld) & 141700,0 \\
Total &
\end{tabular}


Table 9

Total cost of the "Transition \& Go Live" of Fashion \& Co

\begin{tabular}{lr}
\hline Activity & Cost $(€)$ \\
\hline Transition \& Go Live & \\
Tag (non-reusable) & 23 \\
System Test & 150 \\
Traning & 840 \\
Total & 1013 \\
\hline
\end{tabular}

Table 10

Total cost the "Coordination" of Fashion \& Co

\begin{tabular}{lc}
\hline Activity & Cost $(€)$ \\
\hline Coordination & \\
Project Management & 1575 \\
Total & 1575 \\
\hline
\end{tabular}

Table 11

Prospect of the profit and loss with RFID

\begin{tabular}{|c|c|c|c|c|c|c|}
\hline \multicolumn{7}{|c|}{ Profit and loss (RFID) (euro) } \\
\hline Year & 0 & 1 & 2 & 3 & 4 & 5 \\
\hline Revenues & & 0 & 0 & 0 & 0 & 0 \\
\hline Logistic Process: & & 407551 & 402692 & 402692 & 402692 & 402692 \\
\hline Receiving & & 4594 & 4474 & 4474 & 4474 & 4474 \\
\hline Putaway & & 180882 & 176144 & 176144 & 176144 & 176144 \\
\hline Picking\&Sorting & & 92639 & 92639 & 92639 & 92639 & 92639 \\
\hline Shipping & & 129435 & 129435 & 129435 & 129435 & 129435 \\
\hline TAG & & 130752 & 127327 & 127327 & 127327 & 127327 \\
\hline COUNT & & 2304 & 2304 & 2304 & 2304 & 2304 \\
\hline Maintenence & & 1749 & 1748 & 1748 & 1748 & 1748 \\
\hline Reverse Logistic & & 254396 & 254396 & 254396 & 254396 & 254396 \\
\hline Investiment & 160187 & & & & & \\
\hline Revenues - Operative Cost & -160187 & -796751 & -788467 & -788467 & -788467 & -788467 \\
\hline Ammortization & & 53396 & 53396 & 53396 & & \\
\hline EBIT & -160187 & -850147 & -841863 & -841863 & -788467 & -788467 \\
\hline Taxes & & -280549 & -277815 & -277815 & -260194 & -260194 \\
\hline Net Profit & -160187 & -569599 & -564048 & -564048 & -528273 & -528273 \\
\hline
\end{tabular}


Table 12

Prospect of the profit and loss without RFID

\begin{tabular}{lrrrrrr}
\hline & \multicolumn{7}{c}{ Profit and loss (Ø) (euro) } & & \\
\hline Year & 0 & 1 & 2 & 3 & 4 & 5 \\
\hline Revenues & 0 & 0 & 0 & 0 & 0 & 0 \\
Logistic Process: & 0 & 693504 & 686554 & 686554 & 686554 & 686554 \\
$\quad$ Receiving & 0 & 47783 & 46783 & 46783 & 46783 & 46783 \\
C_labels & 0 & 7395 & 7240 & 7240 & 7240 & 7240 \\
C_Reciving_error & 0 & 14221 & 13924 & 13924 & 13924 & 13924 \\
Putaway & 0 & 284421 & 278470 & 278470 & 278470 & 278470 \\
C_Putaway_update IS & 0 & 6399 & 6266 & 6266 & 6266 & 6266 \\
Picking\&Sorting & 0 & 145575 & 145575 & 145575 & 145575 & 145575 \\
C_Picking_Error & 0 & 169 & 169 & 169 & 169 & 169 \\
C_Misplacement & 0 & 169 & 169 & 169 & 169 & 169 \\
C_Picking_update IS & 0 & 52936 & 52936 & 52936 & 52936 & 52936 \\
Shipping & 0 & 215726 & 215726 & 215726 & 215726 & 215726 \\
C_Shiping_Error & 0 & 1377 & 1377 & 1377 & 1377 & 1377 \\
C_Shipping_update IS & 0 & 6195 & 6195 & 6195 & 6195 & 6195 \\
$\quad$ Reverse Logistic & 0 & 423993 & 423993 & 423993 & 423993 & 423993 \\
COUNT & 0 & 57600 & 57600 & 57600 & 57600 & 57600 \\
Total & 0 & 1263958 & 1256421 & 1256421 & 1256421 & 1256421 \\
Revenues - Operative Cost & 0 & -1263958 & -1256421 & -1256421 & -1256421 & -1256421 \\
Ammortization & 0 & 0 & 0 & 0 & 0 & 0 \\
EBIT & 0 & -1263958 & -1256421 & -1256421 & -1256421 & -1256421 \\
Taxes & 0 & -505583 & -502569 & -502569 & -502569 & -502569 \\
Net Profit (euro) & 0 & -758375 & -753853 & -753853 & -753853 & -753853 \\
\hline & & & & & & \\
\hline
\end{tabular}

Table 13

Inbound flows at DC from supplier

\begin{tabular}{lccr}
\hline Month & Hand bags & Small leather goods & Total \\
\hline January & 46309 & 35069 & 81378 \\
February & 30376 & 31469 & 61845 \\
March & 18554 & 16977 & 35531 \\
April & 11384 & 4687 & 16071 \\
May & 40684 & 13914 & 54598 \\
June & 49269 & 30746 & 80015 \\
July & 35318 & 30942 & 66260 \\
August & 25612 & 17512 & 43124 \\
September & 21631 & 39028 & 60659 \\
October & 17277 & 29100 & 46377 \\
November & 10116 & 9428 & 19544 \\
Total & 306530 & 258872 & 565402 \\
\hline
\end{tabular}


Table 14

Outbound flows at DC (to customers)

\begin{tabular}{lcrr}
\hline Month & Hand bags & Small leather goods & Total \\
\hline January & 18420 & 17655 & 36075 \\
February & 48192 & 28907 & 77099 \\
March & 43114 & 33038 & 76152 \\
April & 24328 & 15427 & 39755 \\
May & 4449 & 4021 & 8470 \\
June & 12668 & 10089 & 22757 \\
July & 39746 & 24711 & 64457 \\
August & 21908 & 12110 & 34018 \\
September & 56048 & 44620 & 100668 \\
October & 29921 & 44662 & 74583 \\
November & 7923 & 8683 & 16606 \\
Total & 306717 & 243923 & 550640 \\
\hline
\end{tabular}

